\title{
BMJ Global Heath Need for a standardised procedure classification system in global surgery
}

\author{
Ainhoa Costas-Chavarri,, ${ }^{1,2}$ John G Meara ${ }^{3,4}$
}

To cite: Costas-Chavarri A, Meara JG. Need for a standardised procedure classification system in global surgery. BMJ Global Health 2016;1:e000034.

doi:10.1136/bmjgh-2016000034

Received 31 January 2016 Revised 10 June 2016 Accepted 13 June 2016

\section{CrossMark}

\author{
${ }^{1}$ Human Resources for Health \\ Program, Rwanda \\ ${ }^{2}$ Department of Surgery, \\ Rwanda Military Hospital, \\ Kigali, Rwanda \\ ${ }^{3}$ Kletjian Professor of Global \\ Surgery, Harvard Medical \\ School, Boston, \\ Massachusetts, USA \\ ${ }^{4}$ Department of Plastic and \\ Oral Surgery, Boston \\ Children's Hospital, Boston, \\ Massachusetts, USA
}

Correspondence to Dr Ainhoa Costas-Chavarri; noabelles@gmail.com

\begin{abstract}
'The advantages of a uniform statistical nomenclature, however imperfect, are so obvious, that it is surprising no attention has been paid to its enforcement...,

William Farr, British Medical Statistician, 1839
\end{abstract}

While the WHO's International Classification of Diseases (ICD) has become the standard diagnostic tool for describing diseases and injuries, ${ }^{2}$ there is no equivalent classification system for surgical procedures and interventions that is universally accepted. Why is this important? Estimates reveal that roughly one-third of the global disease burden requires surgical and/or anaesthetic care, but these are only estimates. ${ }^{3}$ The main reason is the dearth of data regarding surgical conditions and interventions, especially in low income and middle income countries (LMICs).

Currently, obtaining data on surgical interventions, including those performed by international organisations, often entails wading through years of aggregate hospital statistics, operating room logs or other paper records, which exist in a multitude of varying formats, classification schema and languages. ${ }^{4}$ Even when available, there is wide variability in the data being collected, as well as significant inconsistencies in the classification of procedures and pathologies requiring surgical intervention. ${ }^{5}$ Indeed, the lack of standardised data collection and processing at the local, national and global level impedes efforts to quantify the volume of surgical met need. More importantly, we are unable to determine what interventions are being performed to address this need.

\section{CLASSIFYING SURGICAL PROCEDURES}

The need to create an international classification system for surgical interventions first arose in the 1970s. Initial development attempts by the WHO, modelled after its successful ICD system, stalled for multiple reasons. ${ }^{6}$ In the mean time, countries with sufficient resources took up the cause, each creating their own procedure classification systems, such as France (Classification Commune des Actes Medicaux-CCAM), Australia (Australian Classification of Health Interventions-ACHI) and the US (Current Procedure Terminology-CPT). While these individual systems function appropriately at the local and national level, the lack of standardisation renders them inadequate for international use and comparisons. In addition, many LMICs in need of a classification system are unable to develop their own.

The growing drive towards electronic health records and the need for interoperability led to the proliferation of independent efforts, such as the non-profit International Health Terminology Standards Development Organization's (IHTSDO) SNOMED Clinical Terms (SNOMED CT) - a hierarchically organised, computer-processable terminology system. More than a procedure classification system, SNOMED CT consists of the largest collection of validated clinical concepts, each with a unique numerical identifier, which can be used for documentation and reporting purposes, specifically when implemented within software applications. In countries with pre-existing systems, cross-maps (links) to SNOMED CT allow for international comparisons and collaboration despite the lack of a universal system; in countries without, it can act as the de facto system, precluding the need for the creation or maintenance of new ones. The advantages of SNOMED CT over other systems include its multilingual format, its extensive concept list (including diagnoses, interventions, procedures and more), improved data aggregation and analysis due to its inherent polyhierarchy and the ability to create subsets-a smaller, defined group of concepts for use in particular settings or specialties. $^{7}$

\section{A CALL AND A MEANS TO ADVOCACY}

Data concerning disease burden and interventions is a key component in determining 
the political prioritisation of global health initiatives. ${ }^{8}$ The paucity of this data in global surgery is thus one of the main factors leading to surgical care being neglected and undervalued as a healthcare priority. In light of this, the global surgery community has rallied-The Lancet Commission on Global Surgery (LCoGS) included surgical volume as one of its core indicators for monitoring the delivery of surgical care and mentioned the need for a universal classification system for health interventions, ${ }^{3}$ the World Health Assembly approved resolution 68.15, recognising that 'relevant and reliable measures of... surgery and anaesthesia are needed for assessment and monitoring,' and urging its member states 'to collect and compile data on...surgical procedures', ${ }^{9}$ and the essential surgery volume of the Disease Control Priorities 3 (DCP3) called not only for 'better estimates' but declared that 'data collection needs to be standardised'. ${ }^{10}$

The need for a standardised procedure classification system in global surgery is imperative. We urge leading groups, such as the LCoGS and the G4 Alliance to advocate at the WHO level for the adoption of SNOMED CT, as the common format for documenting and reporting surgical and non-surgical procedures and interventions. Defined SNOMED CT surgical subsets could be created based on WHO specifications and/or the DCP3 essential surgery package of interventions. The WHO should encourage the inclusion and use of SNOMED CT or its subsets into national surgical plans and electronic case registries. Members of the global surgery community, including international organisations, should incorporate ICD-10 and SNOMED CT into their data collection platforms. Funding bodies should require the use of these classification and terminology systems as part of the monitoring and evaluation component of global surgery proposals. The use of these standardised, universal systems would vastly improve measures of the burden of surgical disease, allow for comparisons of the cost-effectiveness of surgery alongside other health interventions, and further the argument for the inclusion of surgery as an affordable and essential component of healthcare systems.
Twitter Follow Ainhoa Costas-Chavarri at @ainhoac63

Contributors $\mathrm{AC}-\mathrm{C}$ was responsible for the manuscript idea, performed the literature search and wrote the initial manuscript draft. AC-C and JGM contributed equally to the writing of the final draft of manuscript and approved it as submitted for publication.

Competing interests None declared.

Provenance and peer review Not commissioned; externally peer reviewed.

Data sharing statement No additional data are available.

Open Access This is an Open Access article distributed in accordance with the Creative Commons Attribution Non Commercial (CC BY-NC 4.0) license, which permits others to distribute, remix, adapt, build upon this work noncommercially, and license their derivative works on different terms, provided the original work is properly cited and the use is non-commercial. See: http:// creativecommons.org/licenses/by-nc/4.0/

\section{REFERENCES}

1. First Annual Report of the Registrar-General on Births, Deaths, and Marriages in England in 1837-8. http://www.jstor.org/stable/2337712 (accessed Jan 2016).

2. WHO. International Classification of Diseases. 2014. http://www. who.int/classifications/icd/en/ (accessed Jan 2016).

3. Meara JG, Leather AJ, Hagander L, et al. Global Surgery 2030 : evidence and solutions for achieving health, welfare, and economic development. Lancet 2015;158:3-6.

4. Ozgediz D, Jamison D, Cherian M, et al. The burden of surgical conditions and access to surgical care in low- and middle-income countries. Bull World Health Organ 2008;86:646-7.

5. Nickerson JW, Chackungal S, Knowlton L, et al. Surgical care during humanitarian crises: a systematic review of published surgical caseload data from foreign medical teams. Prehosp Disaster Med 2012;27:184-9.

6. WHO. International Classification of Health Interventions. 2014. http://www.who.int/classifications/ichi/en/ (accessed Dec 2015).

7. International Health Terminology Standards Development Organisation. SNOMED CT-The Global Language of Healthcare. http://www.intsdo.org/snomed-ct/ (accessed Dec 2015).

8. Shawar YR, Shiffman J, Spiegel DA. Generation of political priority for global surgery: a qualitative policy analysis. Lancet Glob Health 2015;3:e487-95.

9. WHO. Sixty-Eighth World Health Assembly, Agenda item 17.1. 2015. http://apps.who.int/gb/ebwha/pdf_files/WHA68/A68_R15-en.pdf (accessed 15 Jan 2016).

10. Bickler SW, Weiser TG, Kassebaum N, et al. Global burden of surgical conditions. In: Debas HT, Donkor P, Gawande A, et al. eds. Disease control priorities 3rd edn. vol 1. Essential surgery. Washington DC: World Bank, 2015:9-40. 